\title{
Gaya Humor Mahalabiu
}

\author{
Achmad Faisal, Azizah Fitriah \\ Universitas Muhammadiyah Banjarmasin
}

\begin{abstract}
Humor has two types; there is a positive humor style, an affiliative and self-enhancing humor style, and a negative humor style. It is an aggressive and self-defeating humor style. Mahalabiu is a type of oral literature that contains a dual meaning (ambiguous), having a speech meaning. Usually, the listener defines another meaning or purpose behind Mahalabiu's humor. This study aims to describe Mahalabiu humor as a Banjarese people culture, whether Mahalabiu is a positive or negative style of humor. This research method is qualitative phenomenologies with data collection techniques using interviews as a significant technique and observations. Based on the results of the interview with Informant in this study, there were three people: the type of interview used is a semi-structured interview-the method of observation as a supporting method for understanding more in-depth information related to Mahalabiu humor. Interviews were conducted with three speakers who knew Mahalabiu Humor; they are one cultural expert in South Kalimantan, 1 Banjar Language expert, and 1 Banjar Language expert who is also a native of Alabi. Based on the research results, Mahalabiu humor style has its humor style, which can be positive and negative depending on who is presenting at the right time. Where Mahalabiu has its characteristics in which Mahalabiu depends on the person who delivered it, and depending on the situation, if the moment is right, then it might be that Mahalabiu becomes humorous affiliative humor and self-enhancing humor. However, if the moment is not right then, Mahalabiu will become aggressive humor and self-defeating humor.
\end{abstract}

Keyword: Humor; Indigenous; Mahalabiu; Banjarise

\begin{abstract}
Abstrak
Gaya humor memiliki dua jenis; ada gaya humor positif yang merupakan gaya humor affiliative dan self - enhancing sedangkan gaya humor negative adalah gaya humor yang aggressive dan self - defeating. Mahalabiu merupakan jenis sastra lisan yang mengandung pengertian ganda (mendua), memiliki makna ujaran yang diucapkannya, biasanya sipendengar menafsirkan makna atau maksud lain dibalik ucapan tersebut. Penelitian ini bertujuan untuk mendeskripsikan gaya humor mahalabiu dalam masyarakat banjar, apakah mahalabiu termasuk gaya humor yang positif atau negatif. Metode penelitian ini kualitatif fenomenologis, dengan teknik pengumpulan data menggunakan wawancara sebagai metode utama dalam penelitian ini, jenis wawancara yang digunakan adalah wawancara semi terstruktur. Metode observasi sebagai metode pendukung untuk memahami lebih dalam informasi terkait humor Mahalabiu.
\end{abstract}


Wawancara dilakukan kepada 3 orang narasumber yang memiliki pengetahuan tentang Humor Mahalabiu, yaitu satu orang budayawan di Kalimantan Selatan, satu orang pakar Bahasa Banjar dan satu orang pakar Bahasa Banjar yang juga orang asli Alabio. Berdasarkan hasil dari penelitian gaya humor mahalabiu memiliki gaya humor tersendiri yang mana dapat menjadi positif dan negatif tergantung dari siapa yang membawakan dan pada waktu yang tepat, dimana mahalabiu punya ciri khas tersendiri yang mana mahalabiu tergantung orang yang menyampaikannya dan tergantung dari situasinya apabila momentnya tepat maka dapat jadi mahalabiu menjadi humor yang affiliative humor dan self enhancing humor namun bila momentnya tidak tepat maka mahalabiu akan menjadi aggressive humor dan self defeating humor.

Kata Kunci : Humor, Indigenous, Mahalabiu, Banjar

Humor tidak lepas dari cerita lucu, menggelikan yang memiliki beberapa fungsi yang dibagi menjadi empat fungsi, yaitu fungsi fisiologik, fungsi psikologik, fungsi pendidikan dan fungsi sosial. Humor memiliki fungsi fisiologik yang artinya memberikan dampak yang baik untuk kesehatan fisik, selain itu fungsi psikologi yang dapat meningkatkan kesehatan mental seseorang, selain fungsi lain dari humor dalam hal pendidikan dan sosial dapat memudahkan seseorang untuk berinteraksi dengan lingkungannya (Fitriani \& Hidayah, 2012). Mendengarkan ataupun melihat hal - hal yang lucu biasanya memunculkan perilaku tertawa, perilaku perilaku tertawa yang terjadi akibat interaksi dengan orang lain yang menjadi salah satu indikasi telah terjadinya hal-hal yang lucu yang dirasa menyenangkan. Dalam humor sering kali memunculkan kekhasan suatu daerah dalam hal candaannya ataupun penyampaian humor itu sendiri, sering kali kita lihat tayangan - tayangan yang ada di televisi saat ini gaya humor yang muncul lebih kepada menjatuhkan orang lain ataupun bersikap agresif kepada orang lain untuk dapat menarik gelak tawa. Sudah sangat jarang gaya humor yang tersaji di media televisi, gaya humor positif hal ini lah yang melandasi peneliti untuk mencoba mengangkat gaya humor yang berasal dari daerah Kalimantan Selatan yaitu Mahalabiu.

Salah satu jenis tradisi lisan Banjar yang sangat digemari masyarakat Banjar sekarang ini adalah mahalabiu. Mahalabiu berasal dari kata halabiu (nama sebuah kota) yang mendapat prefks - ma sehingga menjadi mahalabiu. Dalam bahasa Banjar, salah satu fungsi prefks - ma adalah membentuk kata kerja yang bermakna 'mempunyai sifat seperti yang ada pada kata dasar'. Jadi, mahalabiu berarti orang yang mempunyai sifat seperti orang Halabiu (Effendi, 2012). Orang Halabiu dikenal sebagai subetnik Banjar yang gemar membuat 
ceritacerita lucu. Seorang informan, mengemukakan bahawa mahalabiu diperkirakan berasal dari orang-orang Halabiu, sedangkan orang lain selain dari orang Halabiu hanyalah 'sebagai penyambung lidah atau peniru' kebiasaan orang Halabiu. Orang Halabiu, di mana pun mereka berada (di pasar, kedai, rapat, rumah tangga) sering membumbui pembicaraannya dengan canda atau joke yang menggelikan (Effendi, 2012). Penelitian ini bertujuan untuk mengklasifikasikan gaya humor mahalabiu, penelitian ini penting untuk dilakukan di era saat ini, dimana humor - humor yang ada saat ini sudah banyak sekali mengarah kepada menjatuhkan seseorang ataupun bertindak agresif kepada seseorang selain itu penelitian ini juga dapat melestarikan budaya yang ada di daerah Kalimantan Selatan.

Humor berasal dari kata umor yaitu You - moors; cairan - mengalir. Humor adalah stimulus yang dapat memancing tawa pada seseorang, seperti lelucon, ceirta lucu, kartun lucu, situasi memalukan, lelucon praktis, dan sebagianya. Secara sederhana humor di definisikan sebagai sesuatu yang sederhana (Fitriani \& Hidayah, 2012). Humor dan tertawa merupakan hal yang sangat berkaitan, karena tertawa merupakan respon fisik dari stimulasi humor(Martin dkk., 2003). Penelitian terhadap tertawa menunjukkan bahwa efek tertawa baik secara psikologis maupun fisiologis secara psikologis, penelitian menunjukkan tertawa dapat menurunkan level stres.

Martin dkk (2003), menunjukkan empat dimensi humor yakni affiliative humor, self enhancing humor, aggressive humor, dan self defeating humor, menurut Martin humor dikelompokkan menjadi dua dimensi, dimana dua diantaranya bersifat positif dan dua lainnya bersifat negative. Dimensi yang bersifat positif mengacu kepada humor yang bermanfaat bagi kesejahteraan psikologis, dimensi gaya humor yang bersifat positif adalah affiliative humor dan self enhancing humor. Sedangkan humor yang bersifat negatif memilliki kecenderungan untuk menceritkan lelucon dengan mengolok - ngolok spontan untuk menghibur, mengurangi ketegangan interpersonal dan memfasilitasi hubungan, selain itu humor yang bersifat negatif dapat merugikan kesejahteraan psikologis individu itu sendiri bahkan berpotensi merusak kesehatan mental dan fisik, dimensi gaya humor yang bersifat negatif adalah aggressive humor 
yaitu menggoda, mengejek, cemoohan, penghinaan dan self-defeating humor yaitu cenderung mengambil hati orang dengan meremehkan dan menjatuhkan diri sendiri (Martin dkk., 2003).

Kata - kata mahalabiu ini merupakan salah satu cerita humor yang ada di masyarakat Banjar, tetapi diperkirakan mahalabiu berasal daripada orang Halabiu dan orang Halabiu dikenal sebagai subetnik Banjar yang gemar berteka - teki dan membuat cerita - cerita lucu. Sebagaimana penelitian yang dilakukan oleh Yunus dan Ridha yang berjudul "Makna dan Fungsi Mahalabiu Dalam Pertuturan Masyarakat Desa" dalam Jurnal Pendidikan Bahasa Melayu, menjelaskan bahwa mahalabiu dituturkan secara lisan dan berkembang dalam satu lingkungan yang memungkinkan Mahalabiu itu hidup dan berkembang serta diterima oleh masyarakat. Mahalabiu tidak dituturkan seseorang disembarang tempat dengan kata lain mahalabiu yang dituturkan oleh seseorang kepada orang lain harus mempertimbangkan faktor lingkungan sosial dan budaya. Di Banjarmasin, mahalabiu ini sudah dikenal sejak lama, di sebalik kata - kata Mahalabiu tersirat sebuah makna di dalamnya melalui percakapan atau dialog. Kalimat mahalabiu memiliki makna atas ujaran yang diucapkannya, biasanya si pendengar menafsirkan makna atau maksud lain dibalik ucapan tersebut (Yunus \& Anwari, 2016).

Cerita - cerita yang mengandung teka - teki yang dibuat oleh orang - orang Alabio dengan cepat menyebar dan diceritakan lagi oleh orang - orang lain yang mendengarnya. Seperti kebanyakan cerita lisan yang lain (legenda, dongeng, dan lain - lain), Mahalabiu itu direka bentuk lagi oleh seseorang yang lain sehingga menambah kelucuan mahalabiu. Seseorang dapat juga membuat mahalabiu yang baru kurang lebih sama (beranalogi) dengan mahalabiu yang pernah didengarnya. Walaupun mahalabiu itu pada awal mulanya adalah milik orang Alabio, namun kenyataan sekarang, siapapun yang bertutur kata mahalabiu, orang Alabio atau bukan orang Alabio, maka orang itu dikatakan mahalabiu (Effendi, 2012). Tergambarkan bahwa budaya masyarakat Banjar pada dasarnya sangat luas, bahkan dengan satu jenis budaya seperti humor Mahalabiu ini memberikan karakter identik di masyarakat Banjar. Selama ini masyarakat melihat humor Mahalabiu hanya sebagai ungakapan-ungkapan biasa untuk jenaka, 
sebagai salah satu sarana sosialisasi, namun sebetulnya kita dapat menggali lebih lanjut tentang humor Mahalabiu.

Berdasarkan paparan di sebelumnya, peneliti tertarik untuk menggali lebih dalam melalui penelitian ini untuk mendeskripsikan gaya humor mahalabiu dalam masyarakat banjar, apakah mahalabiu termasuk gaya humor yang positif atau negatif. Selain itu bagaimana pengaruh humor Mahalabiu dalam tatanan kehidupan sehari-hari masyarakat Banjar. Penelitian ini akan memberikan pengetahuan dan pemahaman pada masyarakat, khususnya masyarakat Banjar bahwa budaya lokal seperti humor Mahalabiu ini dapat menjadi salah satu bagian dari identitas masyarakat dalam beriteraksi sosial.

\section{Metode}

Jenis penelitian yang digunakan adalah penelitian kualitatif dengan pendekatan fenomenologi, mahalabiu sendiri sangat terkenal di Kota Banjarmasin karena itulah peneliti melakukan pendekatan fenomenologi dalam berusaha untuk mengungkap dan mempelajari serta memahami suatu fenomena beserta konteksnya yang khas dan unik yang dialami oleh individu hingga tataran "keyakinan" individu yang bersangkutan (Hardiansyah, 2015) dengan menggunakan metode wawancara bentuk tidak terstruktur berdasarkan dimensi gaya humor dan arti mahalabiu. Subjek yang di pilih menggunakan teknik purposive sampling yang didasarkan atas ciri - ciri atau sifat - sifat yang dipandang mempunyai sangkut paut yang sesuai dengan tujuan penelitian ini (Hardiansyah, 2015). Jumlah subjek dalam penelitian ini berjumlah tiga orang dengan criteria subjek dalam penelitian ini adalah terbiasa mehalabiu, berjenis kelamin laki - laki dan perempuan, tidak memiliki gangguan komunikasi, bersuku asli Banjar, mengetahui dan memahami istilah mahalabiu dan bersedia untuk berpartisipasi dalam penelitian ini secara utuh. Analisis data yang digunakan adalah Teknik analisis data model Interaktif dengan tahapan; mengorganisasikan data, membaca dan membuat memo data, mendeskripsikan data, pengodean data, mengklasifikasikan data, menafsirkan data, menyajikan dan memvisualisasikan data (Hardiansyah, 2015). 


\section{Hasil}

Wawancara pertama dilakukan pada tokoh budayawan yang berinisal J di Kota Banjarmasin, subjek J salah seorang tokoh budayawan di Kota Banjarmasin yang cukup terkenal. Subjek J terbiasa membawakan humor mahalabiu dalam setiap candaannya dalam kesehariannya subjek J bekerja di Dinas Kebudayaan Kota Banjarmasin karena itulah peneliti memilih subjek J untuk dapat membantu peneliti dalam mengkaji gaya humor mahalabiu. wawancara ini bertujuan untuk memperoleh data - data terkait dalam penelitian ini. Dari hasil wawancara ini diperoleh data mengenai:

Subjek J menjelaskan sejarah, Mahalabiu itu pada dasarnya nama desa. Awal - awalnya nama desa, tapi karena penduduk disana suka bercerita dan setiap ceritanya itu membuat orang tertawa. Subjek J juga memaparkan tentang gaya humor mahalabiu itu seperti apa, mahalabiu itu tergantung dari si pembawa cerita apabila orang yang menyampaikan cerita tersebut suka berbicara, humoris maka ceritanya akan lucu tapi bila si pembawa cerita ini orang nya sudah tidak di sukai orangorang maka ceritanya pun juga tidak akan lucu. Subjek J jugamenambahkan mahalabiu ini bias menjadi humor yang positif dan negatif tergantung situasi dan kondisi ketika menyampaikan dan juga tergantung siapa yang menceritakan.

Wawancara kedua pada seorang pakar ilmu bahasa Indonesia dan daerah, subjek Y juga seorang dosen di Banjarmasin dan juga pernah meneliti mahalabiu dari segi penyampaiannya dalam hal bahasa daerah. Menurut subjek $\mathrm{Y}$, mahalabiu ini awalnya dari nama tempat yang bernama Alabio, karena orang Alabio itu terkenal suka ngomong dan humoris. Selain itu dari subjek Y juga menambahkan terkait mahalabiu; Secara tertulis itu tidak ada syarat khusus untuk mahalabiu namun pada umumnya orang yang mahalabiu itu harus banyak mendengar dan banyak becanda agar terbiasa mahalabi. Humor Mahalabiu ini bisa termasuk humor yang positif dan negatif menurut subjek $Y$, "dalam mahalabiu ini tergantung siapa yang membawakan humornya, siapa yang mendengarkan dan kapan dilaksanakan bila semuanya dengan timing yang tidak pas malah jadi tidak lucu".

Subjek yang ketiga R, seorang dosen ilmu bahasa Indonesia dan daerah, peneliti mahalabiu dan juga orang asli Kota Alabio yaitu awal mula munculnya mahalabiu. "mahalabiu ini awalnya dari warung-warung kopi yang ada di Kota Alabio, di sana rami banyak orang suka 
berbicara dan melawak akhirnya muncul istilah mahalabiu" kata subjek R selain itu "mahalabiu ini lawakan yang bermain dengan kata, ambiguitas jadi tidak semua orang bias mahalabiu kalau orang tersebut tidak memiliki kosa kata yang banyak dan pandai dalam mengolah kata ya simplenya orang yang jago mahalabiu itu umumnya orang yang pandai dalam bertutur atau berbicara". Menurut subjek R juga mahalabiu ini dapat termasuk humor yang positif atau negatif tergantung siapa yang membawakan dan kepada siapa humor ini ditujukan serta kondisi yang tepat, "mahalabiu ini unik dia bias jadi humor yang menyenangkan dan bias juga tidak menyenangkan tergantung si pembawa humor bias membaca situasi kondisi atau tidak, siapa yang mau di tuju dalam mahalabiu ini dan timing nya pas atautidak".

\section{Pembahasan}

Dari hasil wawancara kepada 3 subjek tersebut maka berdasarkan dimensi Humor style, (1) affiliative humor, (2) self enhancing, (3) aggressive humor, (4) self defeating humor dalam mahalabiu ini sangat unik dimana mahalabiu ini dapat menjadi humor yang positif dan negatif, mahalabiu dapat menjadi humor yang positif jika disampaikan pada saat yang tepat dengan orang yang tepat pula tapi bias menjadi humor yang negatif juga apabila momen tidak sesuai meskipun yang menyampaikan adalah orang yang tepat. Berbeda dengan humor style pada umumnya yang hanya ada 4 jenis yaitu affiliative humor, self enhancing humor, aggressive humor, danself defeating humor (Martin dkk., 2003) mahalabiu punya ciri khas tersendiri yang mana mahalabiu tergantung orang yang menyampaikannya dan tergantung dari situasinya apabila momentnya tepat maka bias jadi mahalabiu menjadi humor yang affliative humor dan self enhanching humor namun bila momentnya tidak tepat maka mahalabiu akan menjadi aggressive humor dan self defeating humor.

Mahalabiu memberikan warna tersendiri dalam humornya, dimana mahalabiu jika disampaikan dengan semua moment yang pas maka dapat akan menjadi humor yang lucu yang bermuatan positif (affiliative humor \& self enchancing humor), menurut para subjek tidak jarang pula orang menjadi salah paham atau marah karena mahalabiu hal ini di karenakan moment yang tidak pas saat menyampaikan. Berdasarkan data - data dari hasil penelitian tidaksemua orang dapat melakukan mahalabiu ada beberapa criteria khusus orang - orang yang kemungkinan besar akan berhasil membawakan mahalabiu seperti; pandai berbicara \& 
suka melucu. Jadi mahalabiu juga dilihat dari kemampuan orang yang membawakan humor tersebut sehingga humor yang muncul dari mahalabiu bisa bermuatan hal - hal yang positif namun jika mengabaikan kemampuan orang dalam menghalabiu maka mahalabiu bias menjadi humor yang negatif.

\section{Kesimpulan}

Gaya humor mahalabiu memiliki ciri khas tersendiri tergantung siapa yang membawakan, pada waktu yang tepat dan juga si pembawa humor memang orang yang pandai dalam berbicara sehingga mahalabiu itu sendiri kita dibawakan menjadi hal yang lucu namun apabila syarat - syarat tersebut tidak terpenuhi malah tidak lucu bahkan menjadi humor yang negatif, inilah ke unikan dari mahalabiu. Melihat keunikan dari humor malahabiu itu sendiri, maka peneliti berkesimpulan bahwa mahalabiu termasuk dalam conditional humor hal ini karena mahalabiu dapat masuk dalam dua dimensi humor baik positif dan negative tergantung dari si pembawa/si pencerita humor tersebut.

Saran

Penelitian ini perlu dikembangkan lagi terutama dalam hal metode penelitiannya yang mungkin dapat lebih variatif, serta penambahan subjek penelitian dan mengkaitkan kepribadian dengan mahalabiu karaktersitik yang seperti apa orang yang suka mahalabiu karena ini merupakan penelitian perdana mengenai gaya humor mahalabiu sehingga masih belum ada penelitian sebelumnya ataupun penelitian pembanding, sehingga sangat bagus untuk dikembangkan kembali.

\section{Referensi}

Effendi, R. (2012). Eksistensi Sastra Lisan Mahalabiu bagi Masyarakat Banjar Kalimantan Selatan. LITERA, 11(2).

Fitriani, A., \& Hidayah, N. (2012). Kepekaan umor dengan depresi pada remaja ditinjau dari jenis kelamin. Humanitas: Jurnal Psikologi Indonesia, 9(1), 76-89.

Hardiansyah, H. (2015). Metodologi penelitian kualitatif untuk ilmu psikologi. Jakarta: Salemba Humanika. 
Martin, R. A., Puhlik-Doris, P., Larsen, G., Gray, J., \& Weir, K. (2003). Individual differences in uses of humor and their relation to psychological well-being: Development of the Humor Styles Questionnaire. Journal of research in personality, 37(1), 48-75.

Yunus, M., \& Anwari, M. R. (2016). Makna dan Fungsi MAHALABIU dalam Pertuturan Masyarakat Desa. Jurnal Pendidikan Bahasa Melayu, 3(1), 72-78.

\begin{tabular}{|l|l|l|l|l|}
\hline Submit & Review & Revisi & Diterima & Publis \\
\hline 20-11-2019 & 29-04-2020 sd 06-05-2020 & 13-05-2020 & 04-06-2020 & $10-06-2020$ \\
\hline
\end{tabular}

Achmad Faisal, Azizah Fitriah

Universitas Muhammadiyah Banjarmasin

Email : achmadfaisal89@gmail.com, azizahfitriah@yahoo.com 